cếncentro ciêncla viva algarve
Introducing portable digital devices into science museum outreach activities: how diverse can it be?

\title{
GDULEARN
}

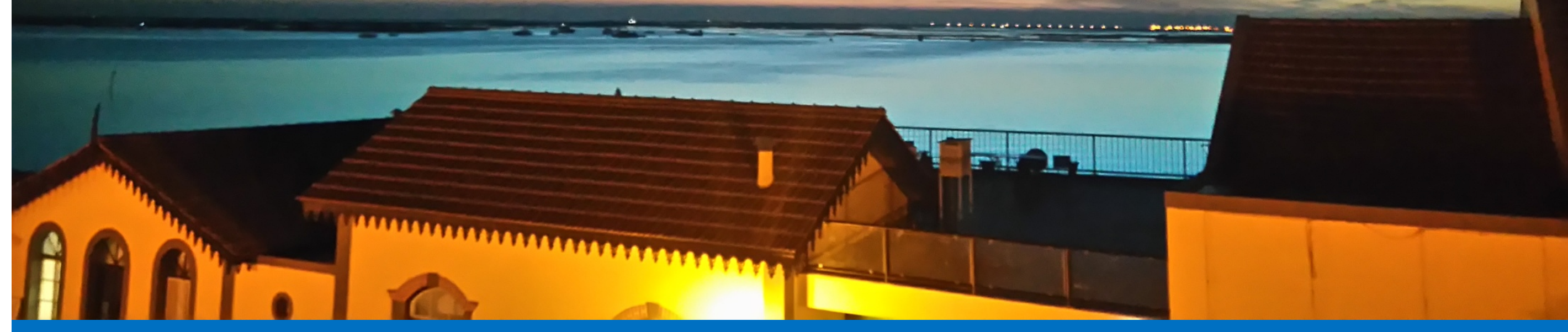

Reis, Emanuel (ereis@ccvalg.pt), A. Colaço, C. Miguel, F. Dias, J. Oliveira, L. Gonçalves, M. Rodrigues, T. Gomes, C. Veiga-Pires Centro Ciência Viva do Algarve : http://www.ccvalg.pt 
centro crêncla viva algarve
Introducing portable digital devices into science museum outreach activities: how diverse can it be?

\section{Who are we?}


CIÊNCIÅlVIVA

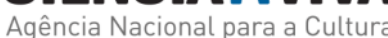

Científica e Tecnológica

(2) UAlg 
cếncentro

crenciąava
Introducing portable digital devices into science museum outreach activities: how diverse can it be?

\section{What is our motivation?}
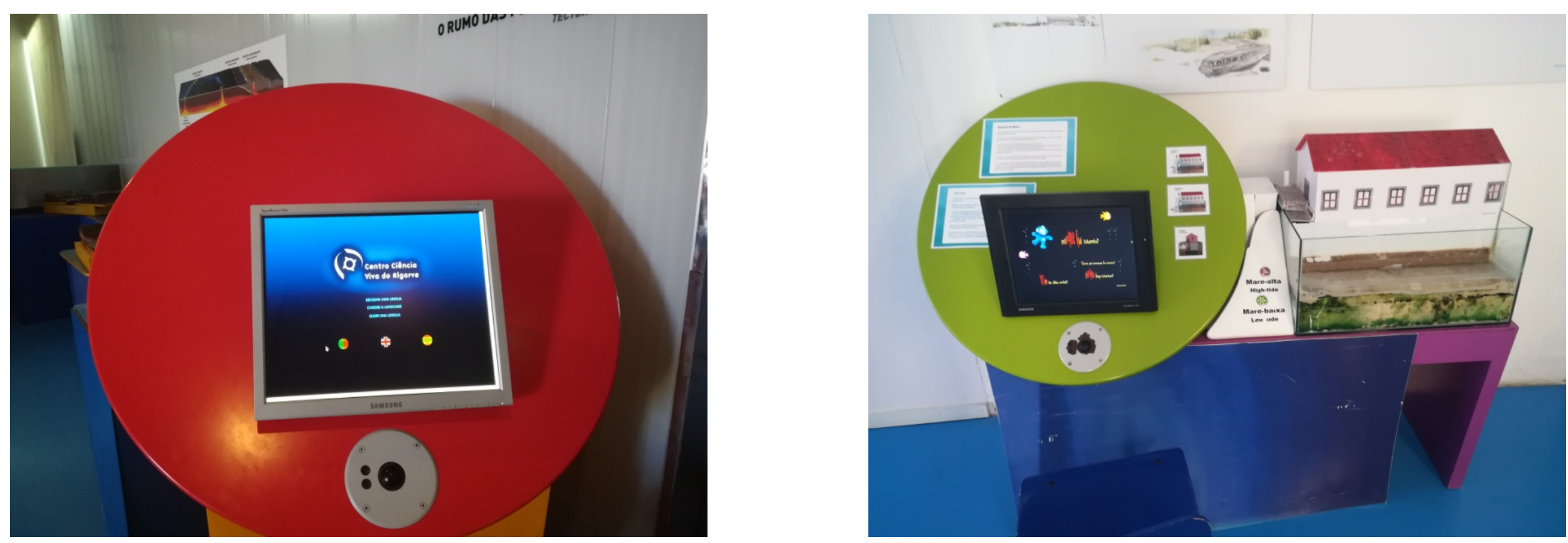


\section{The donation}
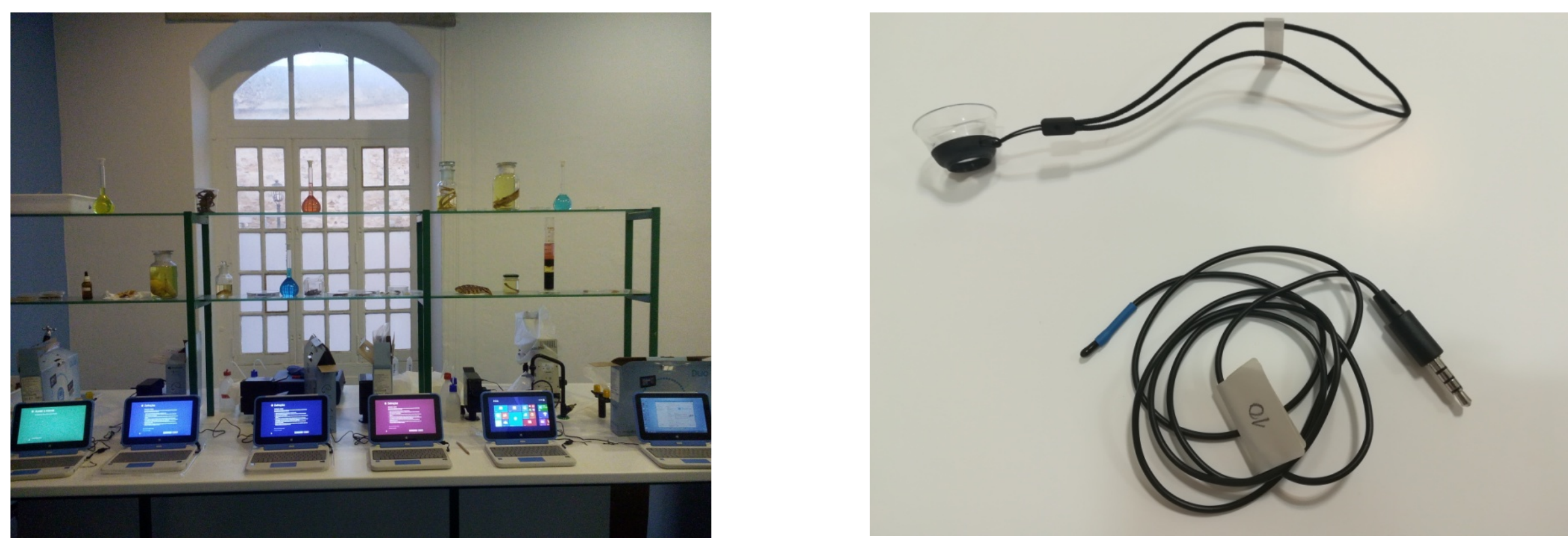

10 x Notebook Magalhães DUO (CeleronN2805-2GB-32-GB-Win 8.1 c/Off H\&S) by jp.group 


\section{$1^{\text {st }}$ year project milestones}

CCVAlg's partners 1st contact with the

donated devices

fev 7, 2017

1st internal trainning about the software

stack (labcam, sparkvue, artrage)

fev 24,2017

Partnership presentation at Ciência Viva

1 Network National Meeting

mar 13, 2017

Follow up meeting between JP.group and CCVAlg. Delivery of 2 devices for software

debugging

mai 2, 2017

Project presentation at SCICOM. pt 2017

out 13, 2017

\section{Follow up}

meeting

between

Delivery of 6 devices at JP.group for

JP.group and

1st activity with students

debugging and software update

CCVAlg.

jun 9, 2017

fev 9, 2018 


\section{EDULEARN}

\section{Indoor outreach activities}



$\triangle$

Observation and identification of marine organisms
Creating multimedia records during CCVAlg's school visits

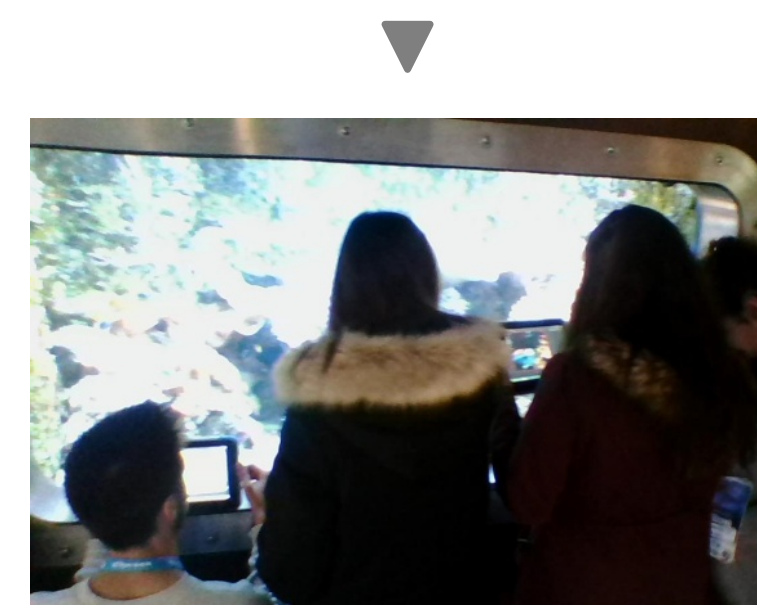

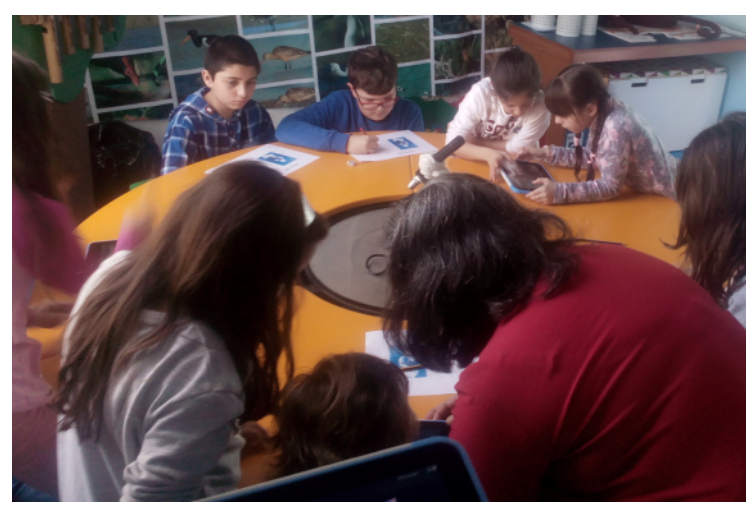

4

Microscopy workshop 


\section{ADULERRN}

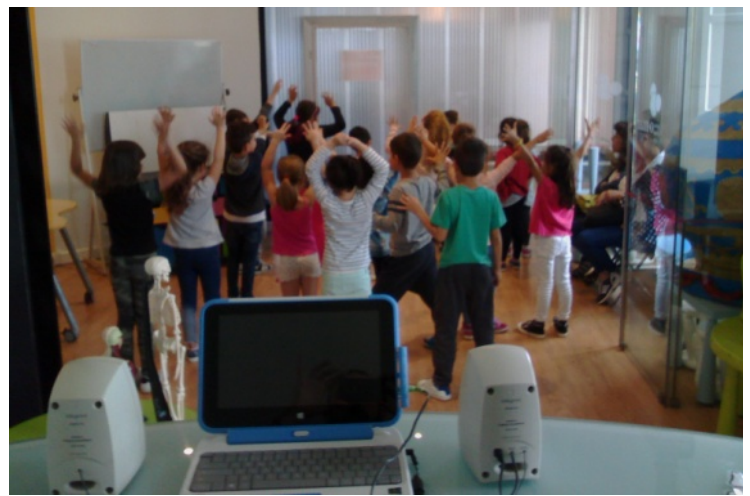

\section{Indoor outreach activities}

Sound workshop

Molecular Modeling


$\triangle$ Holograms

Introduction to the 3D modelling

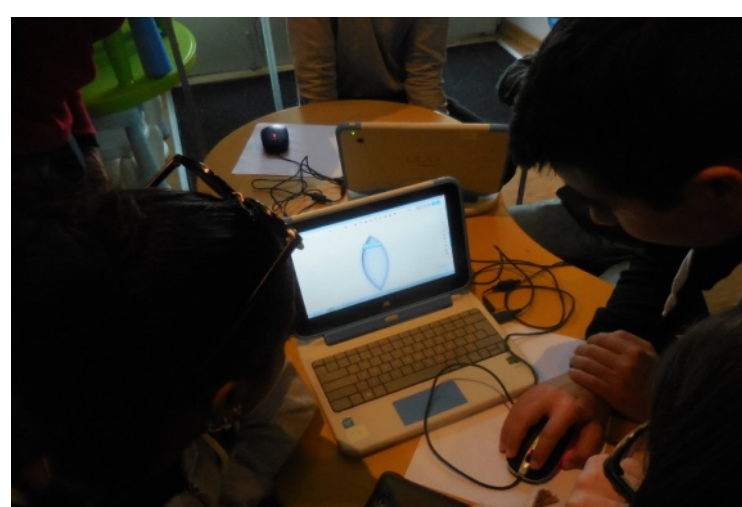


centro

crenciag hava
Introducing portable digital devices into science museum outreach activities: how diverse can it be?

\section{EDULEARN}

\section{Outdoor outreach activities}

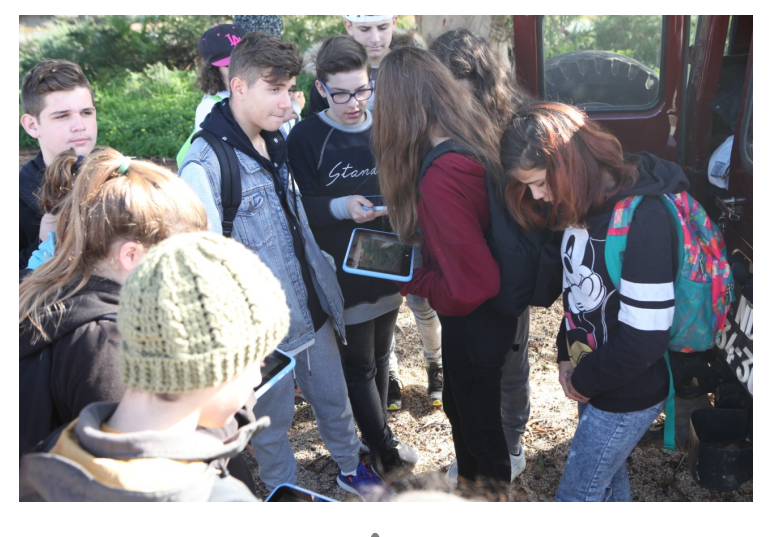

$\triangle$

Birdwatching and vegetal invasive species observation and collection
Microplastic detection

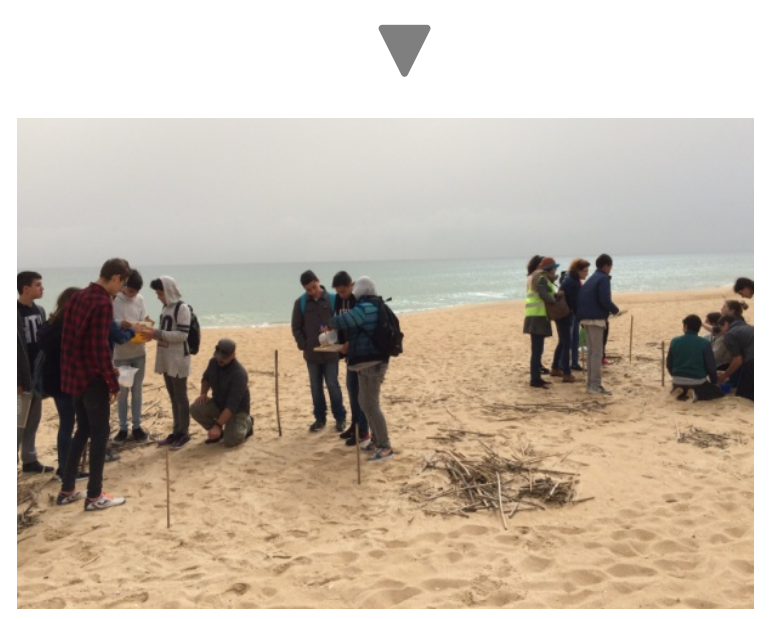

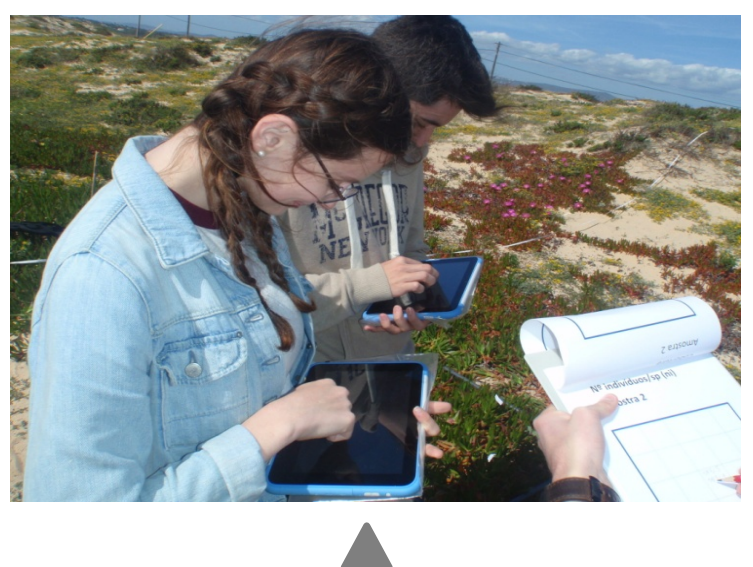

Dune ecology: determination of biodiversity index 
centro

c1encualgarive
Introducing portable digital devices into science museum outreach activities: how diverse can it be?
EDULEARN

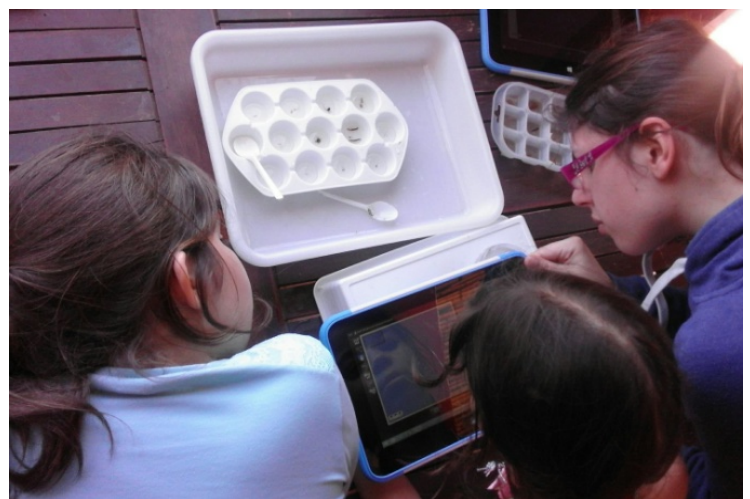

\section{Outdoor outreach activities}

$\checkmark$ Macroinvertebrates monitoring of water masses.

Life under a trunk


$\checkmark$ The beach through a magnifying glasses

Corporate "Peddy tablet"

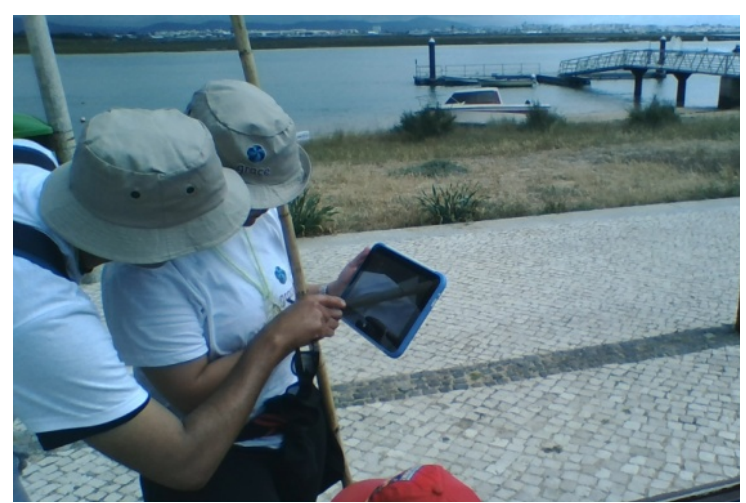


centro

c1encualgarive
Introducing portable digital devices into science museum outreach activities: how diverse can it be?

\section{EDULEARN}

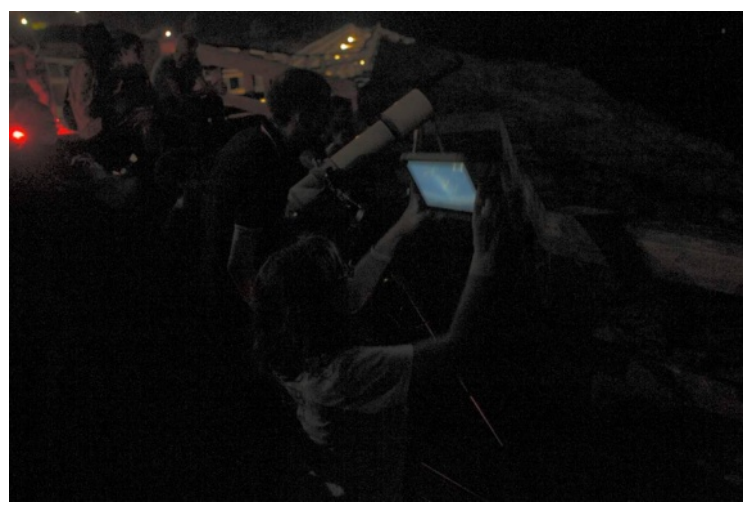

\section{Some outdoor activities}

$\checkmark$ Nocturnal astronomical observations

Activities with thermal probe

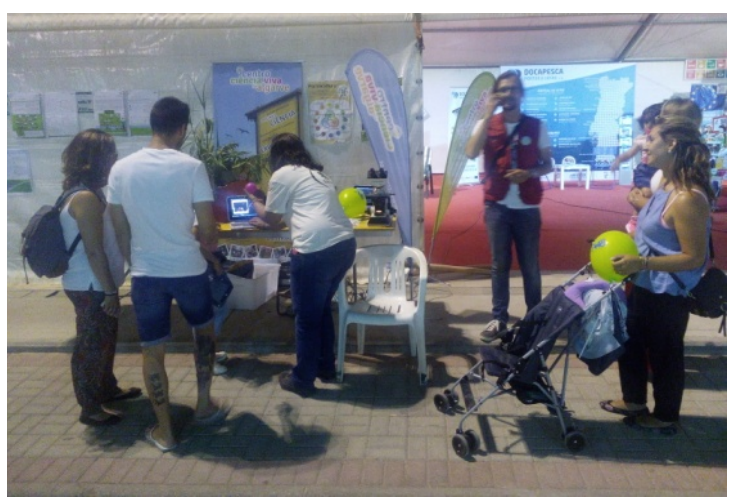

$\triangle$ Labcam Graph Challenge

Submarine acoustic measurement
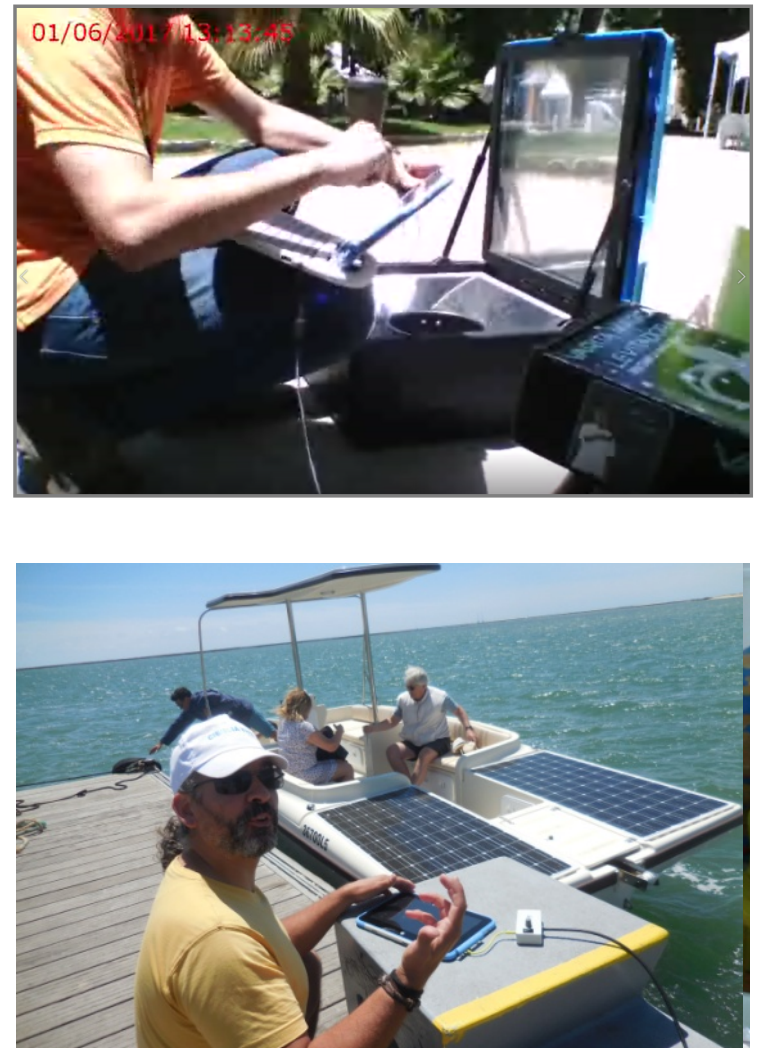
cệcentro c1encualgarive
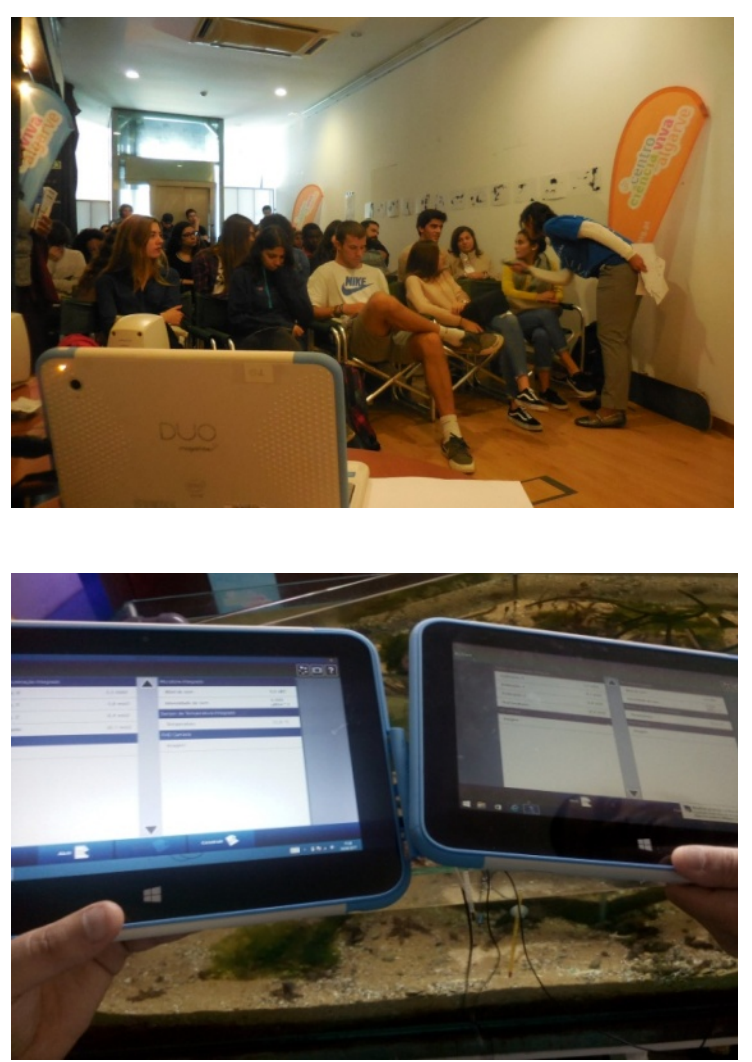

\section{Other aplications}

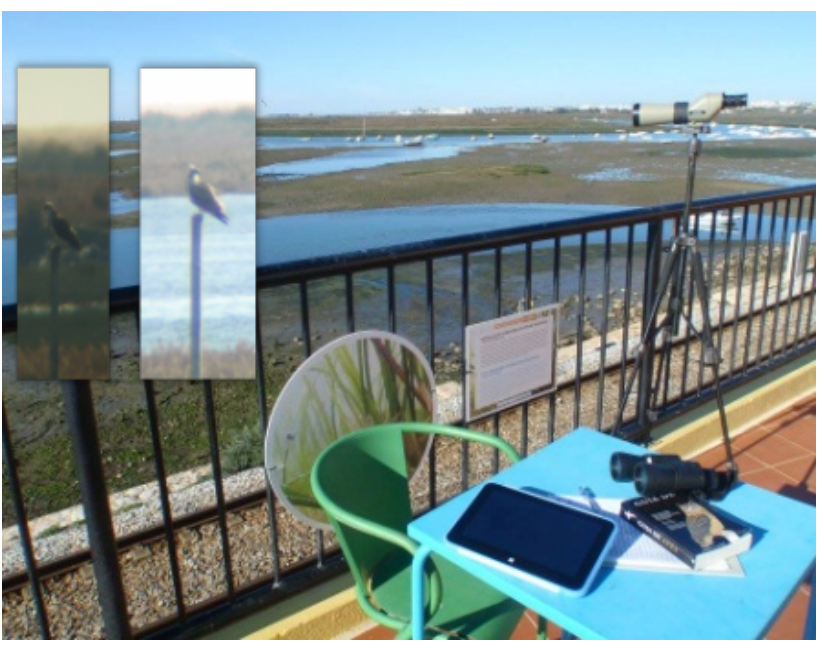

\section{EDULEARN} museum outreach activities: how diverse can it be?
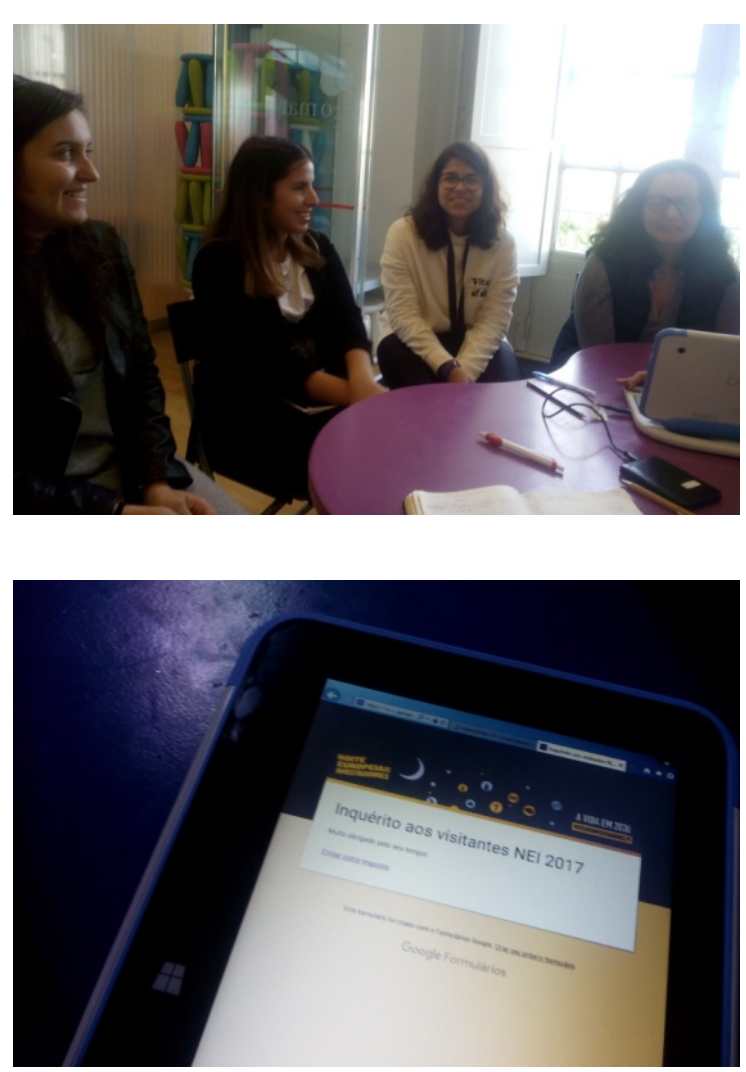


\section{After $1^{\text {st }}$ year}

\begin{tabular}{l|c}
\hline \hline Type of initiative & $\#$ events \\
\hline Astronomical observation & 5 \\
\hline Debate/assembly & 3 \\
\hline Field activity & 12 \\
\hline Hands on activity & 31 \\
\hline Institutional event & 15 \\
\hline Scientific communication & 1 \\
\hline \hline
\end{tabular}

\begin{tabular}{l|c}
\hline Field of knowledge & \# events \\
\hline Maths and Modelling & 1 \\
\hline Physics and Chemistry & 9 \\
\hline Earth Sciences & 2 \\
\hline Space Sciences & 6 \\
\hline Life Sciences & 31 \\
\hline Social Sciences & 3 \\
\hline Applied Sciences & 13 \\
\hline History and Culture & 3 \\
\hline \hline
\end{tabular}

1 Year | 54 Initiatives (17 indoor +37 outdoor) | 3291 participants 


\section{Main reflections}

1) Project with a regional impact that added value to the CCVAlg offer

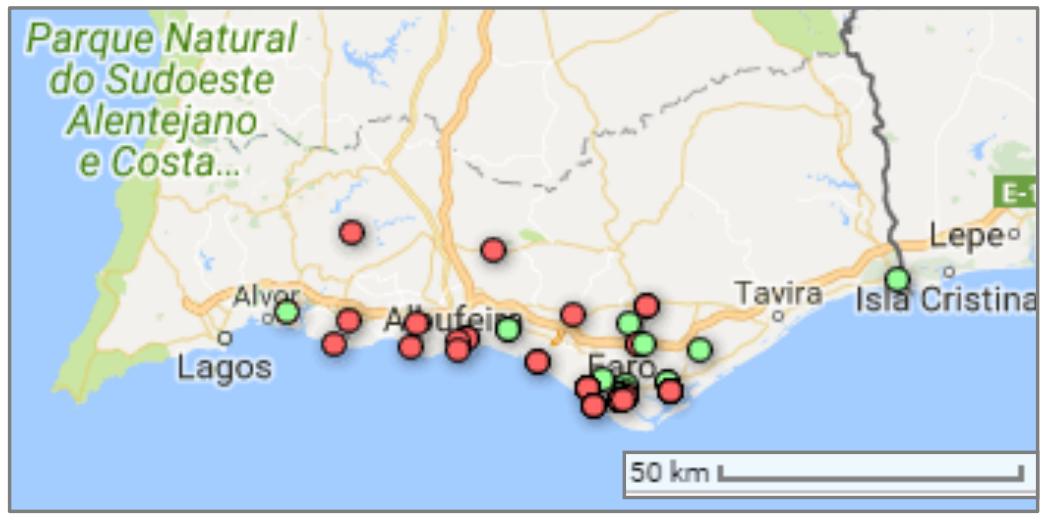

- Origin of a group that interacted with the devices in CCVAlg

Local of an outdoor activity with the devices
2) Informal education environments like science museums are interesting to ITC pilots because:

$\checkmark$ No pressure of formal curricula or evaluation moments

Flexibility for testing design and implementation

Easy access to a large number of testers

$\checkmark$ Financially sustainable

$\checkmark$ Good for activities' development 


\section{Further developments}

Inclusion of new devices and/or new software under consideration Involve other partners in the project

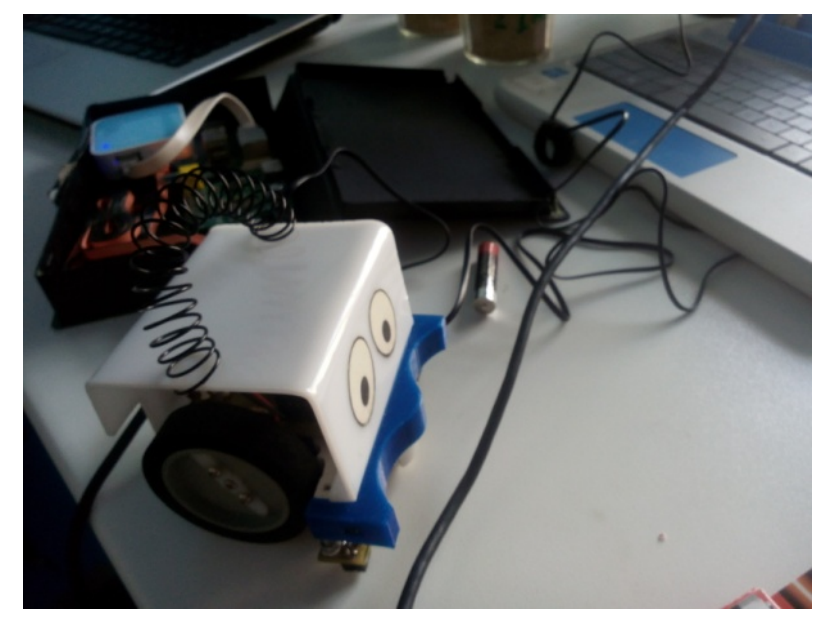




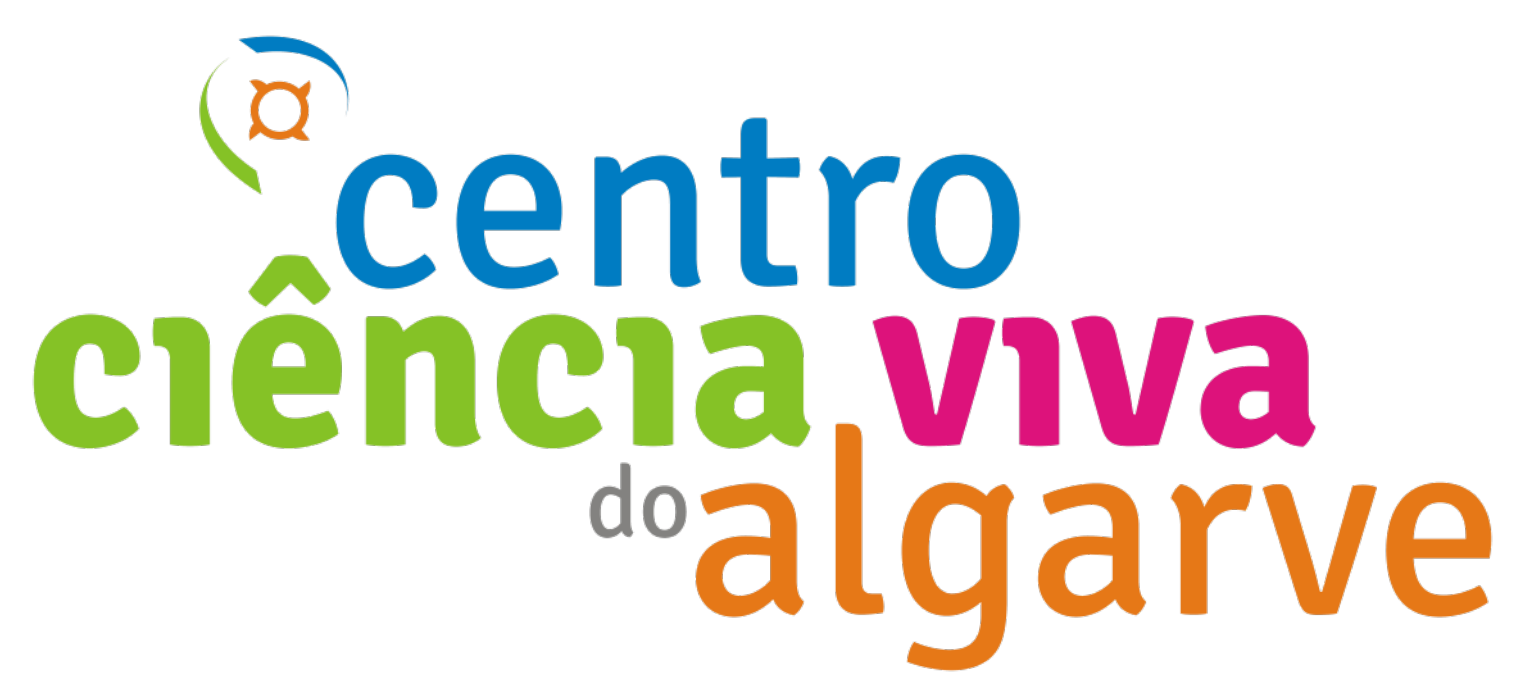

Thank You! 